\title{
Public Trust in the Health Care System in a Developing Country
}

Dexnell Peters and Farid F. Youssef

Department of Preclinical Sciences, The University of the West Indies, St. Augustine Campus, Trinidad \& Tobago.

Correspondence: Dr. Farid F. Youssef, Department of Preclinical Sciences, The University of the West Indies, St. Augustine, Trinidad \& Tobago.

Tel: 1.868.645.2640 Ex. $4621 \quad$ Fax: 1.868.645.3615 farid.youssef@sta.uwi.edu

Short Title: Public Trust in Health Care

The abstract has 244 words.

This manuscript consists of 4047 words, 29 pages, five tables and two figures. 


\section{Public Trust in the Health Care System in a Developing Country}

Short Title: Public Trust in Health Care

Broadly defined, trust in the health care system is concerned with how the public perceives the system and the actors therein as it pertains to their ability to both deliver services and seek the best interests of their clientele. Trust is important because it impacts upon a range of health behaviors including compliance and ultimately affects the ability of the health care system to meets its goals. While several studies exist on public trust within the developed world few studies have explored this issue in developing countries. This paper, therefore, assesses public trust in the health care system of a developing small island nation, Trinidad and Tobago (T\&T). A cross-sectional survey of adults was conducted using a questionnaire that has been successfully used across Europe. We report that trust levels in the health care system in T\&T are relatively low with less than fifty percent (50\%) of persons indicating fair trust in the health care system. In addition individual health professionals also did not score highly with lowest scores found for nurses and complementary therapists. Results on four out of five dimensions of trust also demonstrated scores significantly lower than those reported in more developed nations. Open ended comments supported these findings with the majority of persons indicating a lack of confidence in the health care system. These results may reflect the reality in the wider developing world and we suggest that bolstering trust is a needed area of focus in the delivery of health care services throughout the nation.

Keywords: Health care evaluation, quality improvement, public trust, public perceptions, developing world, Trinidad and Tobago 


\section{Introduction}

Health and the health care system form critical pillars of any society. At its core the health care system is a relational one with trust existing as the central tenet upon which these relationships rest (Gilson, 2003). In this context trust is the expectation that health care providers will demonstrate knowledge, skill and competence, acting in the patient's best interest with beneficence, fairness and integrity. On the micro level trust increases the effectiveness of the doctor-patient interaction, creating greater levels of patient satisfaction and improving compliance. On a macro level trust is crucial in ensuring societal impact through met expectations and increasing influence (Davies and Shield, 1999; Pearson and Raeke, 2000; Lee et al., 2007).

Existing literature has determined two types of trust: interpersonal trust and public trust. Interpersonal trust is concerned with trust placed by one person in another and implies the transfer of control over certain resources, based on the hope that this will serve in the person's best interests (Straten et al., 2002; van der Schee et al., 2007). Public trust is "trust placed by a group or person in a societal institution or system" (van der Schee et al., 2007). It is a generalized attitude of confidence or lack of it that can be informed by personal experience, experience of others and the mass media (Mechanic and Schlesinger, 1996; Straten et al., 2002; van der Schee et al., 2006).

This study is specifically concerned with public trust, which is related to interpersonal trust and ultimately informs it. Public trust can provide a good indicator of the level of 
support for the health care system as a whole and for determining the kind of systematic changes that may be necessary. There may also be a link between attitudes of public trust and a person's behavior (Straten et al., 2002). In this regard, public trust can have an impact on, for example, people's compliance with medical treatment. If this is the case, then assessing public trust is important both to the health care system and its users.

Broadly defined, public trust in the health care system can be assumed to simply be concerned with whether there is confidence or not. Despite this public trust is a multidimensional concept. The literature highlights differing considerations on what are these dimensions. Gray (1997) notes, for example, only two dimensions, technical competence and prioritizing patients' interests. Others have expanded on the number of dimensions concerned with public trust (Mechanic, 1996; Straten et al., 2002). We have to a large extent relied on the dimensions ${ }^{1}$ determined by the Netherlands Institute for Health Services Research which have emerged from extensive interviewing of the general public and been successfully applied to several surveys within Europe (Straten et al., 2002; Calhan and Sanford, 2004; van der Schee et al., 2006; van der Schee et al., 2007).

Public trust is one of the medical profession's best assets; it is trust that has allowed for the elevation of the profession's status and autonomy (Mechanic, 1996). Trust in the medical profession has historically remained high for it was based on the assumption that members of the profession would be altruistic. However this altruistic ideal began to be

${ }^{1}$ These dimensions are listed in the methods section of the paper. 
challenged in the 1960s when some argued that "medicine had abused its monopoly to further its own interests, had self-regulated poorly, and... [was] more interested in serving their members than society" (Cruess and Cruess, 2004). From this point on the literature on public trust in health care indicates a general decline of trust. For example reports from the late eighties indicate that $89 \%$ of Americans, $69 \%$ of Britons and $43 \%$ of Canadians lacked confidence in their health care system (Blendon and Taylor, 1989).

By the turn of the $21^{\text {st }}$ century there was a peak in opinions of thought concerning public trust of doctors and health care systems, which detailed an erosion of trust (Pearson and Raeke, 2000; Mechanic, 2001; Straten and Friele, 2002; Maynard and Bloor, 2003; Gilson, 2003; Mechanic, 2004; Calhan and Sanford, 2004). Many felt that rapid changes to health care systems threatened the medical profession globally. A report from the United States (US) noted that trust in health care has been in decline for some time and that this trend has created less confidence in the current and future health care system (Shore, 2007). Britain too faced similar challenges as this period was marked by the occurrence of a number of major scandals and health care disasters (Calhan and Sanford, 2004; Checkland et al., 2004). Essentially, the flurry of empirical studies and perspectives pointed to a crisis of trust in health care systems.

These studies have, for the most part shed light on the developed world and therefore provide an insightful but imbalanced global perspective. The importance of trust to health care systems is at least as relevant and perhaps more so in the developing world given the historical context in which modern health care has emerged and the critical lack of 
infrastructure and human resource that exist in many emerging nations. A brief historical look at the Caribbean region is a good example to establish the role of trust. While those enslaved made use of services from European physicians, they still relied on support from traditional healers. This reliance was at least partly due to lack of trust in Western medicine by the enslaved (Handler, 2000). Over time the medical profession, including colonial physicians practicing in the Caribbean, also benefitted from the trust as evidenced in a class of indigenous doctors emerging at the turn of twentieth century (West Indian Royal Commission, 1945).

In spite of an extensive network of colonial hospitals and health centres that gradually developed in the Caribbean region, population growth "outpaced the development of medical facilities and challenged the already problematic health care system of the islands" (McCollin, 2009). In recent times the rise of chronic non-communicable diseases, a burgeoning population under thirty-five and increased life expectancy have continued to exacerbate the challenges. This example of the Caribbean highlights the issues of resource shortage, infrastructural limitations and financial constraints that have become typical of health care problems in the developing world.

These problems have all contributed to the decline in trust of the medical profession over the years and have made the health care problem even more difficult to address. As such policy makers and aid agencies continue to pour money into health care projects as the primary means of addressing these challenges. While much of this spending is legitimate, the lack of trust cannot be solved by random expenditure. Physician trust levels play a 
notable role in patients' decisions to commit to medication regardless of financial circumstances. Those with limited resources are less likely to comply when trust was never established between patient and physician (Piette et al., 2005). An example of failure to establish trust occurred in 2003, when the public boycotted a Polio Immunization Campaign in northern Nigeria as a result of an erosion of public trust in western health interventions (Jegede, 2007). This study therefore aims to assess public trust in health care in a twin-island state in the Caribbean, Trinidad and Tobago (TT). It attempts to add empirical data to the relatively few studies in the developing world on the issue of public trust in health care providers and health care systems.

Trinidad \& Tobago is the most southern Caribbean island less than 10 miles off the coast of the South American mainland. With a population of approximately 1.25 million its population benefitted from the discovery of oil in the 1970's which has produced an urbanized environment and level of development that is not typical of other Caribbean nations with just over $25 \%$ of the population living in a rural setting (CARICOM Capacity Development Program, 2009). The TT government offers free health care for all and spends approximately 6\% of total GDP on healthcare. When comparisons are made on a spending per captia basis TT ranks 39th among all nations (WHO, 2013). Despite this investment there are repeated reports of chronic shortages at the nation's hospitals at it pertains to manpower, bed spaces and pharmaceuticals. This has resulted in a booming private healthcare sectors that has resulted in the increasing cost of health care for many. 


\section{Methods}

\section{Questionnaire}

This study, approved by the Faculty of Medical Sciences Ethics Committee at the University of the West Indies, (UWI) used a validated questionnaire to gather data on public trust of the health care system in T\&T. After review by the authors and an expert in survey design within our local setting the questionnaire was adapted from one originally developed in the Netherlands and later used in a multi-national comparison of public trust in Europe (Straten and Friele, 2002; van der Schee et al., 2007). This included a version that was translated into English and used in the United Kingdom.

The questionnaire consisted of three sections. The first sought to gain demographic data and personal preference for health care professions and institutions. Section two contained a four-point Likert scale from 'no trust at all' to 'a great deal of trust' as a

measurement scale for general practitioners, specialists, nurses, complementary therapists, pharmacists, dentists and the health care system as a whole. Participants were also able to state whether they did not know or had no opinion. Whereas in the original version of the questionnaire participants were required to respond to questions about fifteen different health care service organizations and providers we only included seven. This was because many of the services listed in the original survey are unfamiliar in the Trinidad \& Tobago context and rarely accessed (e.g. health service managers, home care services). In addition almost all of the additional services fall under the ambit of the National Health Service and are generally viewed as such by the public. The final section 
mirrored the original questionnaire used in the UK and examined five dimensions of trust in the health care system. These included:

i) patient-centered focus of health care providers;

ii) effect of policies within the health care system;

iii) expertise of providers;

iv) quality of care;

v) communication and information provision.

Each dimension was derived from various items that contained a statement related to trust in health care that was measured on a four-point Likert scale and to which persons were asked to indicate their opinion from 'strongly disagree' to 'strongly agree'. Participants were also able to note whether they did not know or had no opinion for this section.

\section{Sampling}

The population in TT is spread across the island but with distinct population clusters around a major town/city in the north-west, eastern, central and southern regions of the country. Each of these towns is associated with at least one major shopping centre and transportation hub which large sections of the population will utilize on a daily basis. We therefore visited six different public centres in these regions and made use of convenience sampling to distribute the questionnaires to persons over the age of eighteen.

The estimated population of T\&T is 1.25 million persons of which approximately $75 \%$ are over the age of eighteen. Therefore drawing from this population with a 95\% 
confidence interval a minimum sample size of 384 persons was determined. To ensure we achieved this number approximately 790 persons were approached and invited to participate in the survey to which 520 responded positively. However upon review of the submitted questionnaires several persons did not complete entire sections of the survey and so these were not used for the analysis. In total 495 valid questionnaires were identified and analyzed. While distributing the questionnaires it became apparent that persons were very interested in the study and desirous of giving further feedback. As such the questionnaire was revised to include a fourth section that invited persons to submit any other written comments. The last 140 questionnaires distributed included this additional section and of these seventy-five persons completed this section.

\section{Data Analysis}

The data were inputted and analysed using the SPSS version 19. Percentages responses to each item on the Likert scales were calculated and presented. However in order to enable comparisons with other published studies and given that the Likert scale used consisted of progressive positive values the mean score \pm standard error were calculated for each variable. Consistent with previous studies ANOVA was used for comparison among the biographical data and other items of the questionnaire. As noted previously, a comments section was included in the questionnaire at a later point. A thematic analysis was done using themes identified in this section of the questionnaire. 


\section{Results}

Overall 495 questionnaires were used for analysis yielding a response rates of $63 \%$. In terms of ethnicity (46\% Indian, 27\% African and 24\% mixed) and age distribution (70\% between the ages of 18 and 40) our sample tended to approach the national average. This was also true for distribution according to environment with $25 \%$ of the sample classifying themselves as living in a rural. However among our sample there was a larger proportion of women (67\%) compared to the national profile (50\%). The demographic data of our sample is summarized in Table 1 and this can be compared with data from the Trinidad \& Tobago 2010 National Census found at http://cso.planning.gov.tt/census.

Percentage responses for trust in each of the health professionals are summarized in figure 1. From this is can be seen that specialists (74\%) and dentists (72\%) had the most persons indicating fair or a great deal of trust. Lowest percentages were found for nurses (42\%) and complementary therapists (39\%). However the health care system as a whole demonstrated the lowest percentage of persons indicating fair or a great deal of trust yielding a percentage score of $34 \%$. This was supported by ANOVA in which means scores were compared and there was an overall significant difference in trust $(F=61.76$; $\mathrm{df}=6$; $\mathrm{p}<0.001$ ) with GPs, specialists, dentists and pharmacists all scoring significantly higher than nurses and complementary therapists. Trust in the health care system as a whole was significantly less than that for all the individual professions $(p<0.01)$ except for complementary therapists. There were no significant effects of gender upon trust scores for any of the professions or the health care system. 
Five dimensions of trust were examined and the results are summarized in figure 2 and table 2. The mean score for patient-centered focus of health care providers was $1.82 \pm$ 0.03. Females scored significantly lower on this dimension $(1.93 \pm 0.06$ vs $1.77 \pm 0.03$; $\mathrm{p}<0.05)$. The score for communication and provision of information was $1.96 \pm 0.03$ and the score for quality of care was $1.82 \pm 0.03$. Professional expertise scored lowest, $1.71 \pm$ 0.03 , and the impact of macro policies on health care scored $1.91 \pm 0.03$. Gender had no effect on any of these other four dimensions. Level of education had no effect on any dimension except communication and provision of information $(\mathrm{F}=4.14 ; \mathrm{df}=2 ; \mathrm{p}<0.05)$. Persons who had attained a primary school education were significantly more satisfied with the level of information provided when compared to persons who had benefitted from secondary and tertiary education. Ethnicity, religion and place of abode had no significant effect on any of these dimensions.

There is a general consensus that the health care system in Trinidad and Tobago is in dire need of improvement. A thematic analysis conducted on the seventy-five open-ended comments are summarized in Table 3. The comments endorsed the findings of the questions where low levels of trust were seen in the quantitative data. $97 \%$ of the comments received mentioned significant flaws in the system. $16 \%$ of these comments spoke very generally about the health care system, pointing out the need for overall improvement. Though the majority of comments mention flaws in the system and the need for improvement, 3\% did provide positive reviews of the health care system. 


\section{Discussion}

The main findings of this study are that trust levels in the health care system in T\&T are relatively low with less than $50 \%$ of persons indicating great or fair trust. These findings are consistent with studies on patient satisfaction conducted in T\&T fifteen years ago (Phillips, 1996). Despite the rise of private health care in T\&T, the health care system is primarily funded by tax revenues and thus our findings may reflect a general dissatisfaction with the government and their failure to meet the social needs of the population. This idea is supported by the fact that trust in a number of health professions including doctors (65\%), specialists (74\%), dentists (72\%) and pharmacists (65\%) was much higher. Thus it seems that while there is general trust in the professionals as individuals, users are far more concerned about the ability of the system to meet their needs.

Interestingly nurses scored particularly poorly with only $42 \%$ of persons indicating a great deal or fair trust. This is in sharp contrast to data from North America and Europe and could reflect that nurses are most strongly associated with the health care system as they often represent the first point of contact with patients and are the primary caregivers in the hospitals and health centres (Calhan and Sanford, 2004; van der Schee et al., 2007; Donelan et al., 2008; EKOS, 2011). Thus nurses in T\&T interface with patients to a far greater extent than other members of the health care team and thus may bear the brunt of the lack of confidence attributed to the entire system as a whole. An alternative explanation comes from a similar study out of Germany that also found low trust scores for nurses in that population (van der Schee et al., 2007). The authors noted that Germans 
score highly on the Hofstede's cultural dimension of Uncertainty Avoidance ${ }^{2}$, which relates directly to trust in expert knowledge. Interestingly, T\&T’s score is only slightly lower than Germany's suggesting a failure of the local population to recognize nurses as skilled professionals in their own right (Hofstede, 1984).

When the results of our study are compared to other studies T\&T nationals demonstrate significantly lower trust than persons from the United Kingdom, Holland and Germany, see Tables $4 \& 5$. Interestingly the scores in our study are similar to scores in these nations when studies on public trust first emerged. Since then public trust has increased but the reasons for this uptick remain unclear (Calnan and Sanford. 2004; van der Schee, 2007; EKOS, 2011; Ipsos Mori, 2012). It has been suggested that the increase seen in these developed countries reflects the efforts of governments and their ability to convince the general public of their strong focus on health care. This may be lacking in Trinidad \& Tobago as evidenced by the negative press that the health care system regularly receives and the fact that less than $6 \%$ of GDP is spent on health services.

Alternatively lower scores in T\&T could reflect low health care professional to patient ratios, failing infrastructures, long waiting times and limited access to specialized services. In this case as previously alluded low trust may not actually reflect trust but general dissatisfaction with the services being offered by the government (World Health

\footnotetext{
2 Uncertainty Avoidance is one of the five dimensions of Geert Hofstede's Cultural Dimensions Theory. This describes the effects of a society's culture on the values of its members, and how these values relate to behavior, using a structure derived from factor analysis. The other four dimensions are Power Distance, Individualism, Masculinity vs Feminity and Long Term vs Short Term Orientation.
} 
Organization, 2001). These findings may be typical of developing nations but studies out of South Africa, Mexico and to some extent Bangladesh demonstrate higher levels of user satisfaction (Aldana et al., 2001; Kroeger and Hernandez, 2003; Myburgh et al., 2005). Though these studies did not focus on trust specifically the results are surprising given that T\&T's scores on all indicators of quality of health care are much higher than those found in the studies mentioned above. This again may suggest that in our setting there is a significant problem with the perception of services being offered by the public health system. Indeed results from a recent Mori poll in the UK highlight the importance of public perceptions even when problems still exist within the health care system (Ipsos Mori, 2012). The survey notes, "The public increasingly believes that the NHS is working to tackle inefficiency. This wave of the survey records the lowest ever number of mentions of bureaucracy and top heavy management as one of the biggest problems facing the NHS (14\%). Although less than half (46\%) agree the NHS is doing everything it can to tackle waste and inefficiency, these perceptions have improved over the last 18 months (from 36\% agreeing in December 2010)”

An evaluation of the scores of the five dimensions of the health care system demonstrated that these too were low. None of the dimensions surpassed a mean score of 2.0 with Communication and Provision of the Information scoring the highest and the Level of Expertise of Providers as the lowest recorded, see Figure 2. When examining the individual questions the lowest scores revolved around the issues of waiting times being too long, the negative effects of cost-cutting in the health care system, doctors' errors in 
making right diagnoses and more generally their inability to address all the complaints of patients at one visit, see Table 2 .

When the various dimensions are also compared with the international comparison study the trend remains the same, with the exception of the impact of macro policies on health care. An examination of the individual items further exaggerates the significant difference between the scores in T\&T with those of other developed countries, see Table 5. These issues can perhaps shed light on some of the issues that emerge more sharply in comparing the problems of health care problems in developing and developed countries.

Interestingly, T\&T scored highest in statements derived from the 'Effect of Policies within the Health care System' dimension. While all the scores are fairly low it may appear that in T\&T and perhaps in other developing countries, matters of policy are of less concern than in more developed countries. This can possibly be explained by a tendency of the people of T\&T and perhaps the wider developing world to be more accepting and less likely to challenge government policies and practices.

Comments from open-ended questions complement the quantitative data, highlighting the relatively low trust levels in $\mathrm{T} \& \mathrm{~T}$ with $97 \%$ of responses having negative trust experiences. While not the most frequently stated comment, some respondents had an issue with doctors working in both public and private health care. Respondents felt that while some doctors give bare minimum efforts in the public health sector, the same doctors offered better service in their private practices. One person noted that doctors 
place "too much emphasis ... on their private practice and how much more their financial budget will increase working privately and [if they leave] the public hospitals unattended." Similarly, another person complained of doctors using the public sector to refer patients to their private practice, taking advantage of services not available in the public sector. Relevant to those respondents who access public health care, this may help to explain their inclination towards low levels of trust in doctors. With reference to the statement that 'doctors are well regulated' only $16 \%$ responded positively to this statement.

Finally it should be noted that this study has certain limitations that should be considered when attempts are made to generalize our findings. In particular funding restrictions resulted in sampling being confined to primarily a sub-urban setting. As such much of the rural population that does not transit into the towns and cities may have been excluded. However it should be noted that (i) TT is somewhat urbanized nation and this urbanization has been increasing during the past 15 years resulting in the majority of the population now leaving in urban and suburban areas and (ii) 25\% of persons identifying themselves as living in rural areas. Overall in many respects our sample approximated the national averages in terms of age profile, education, ethnicity and religion. The one major difference between our sample and the national population is that our survey was made up of $67 \%$ of women. The reasons for this are not clear thought it might reflect women being more comfortable completing the survey and expressing their opinions in such a forum. 
This study is also limited by the use of a self-report survey. Therefore it is difficult to determine if persons responded based upon social norms and if their responses are consistent with behaviors. However the desire of participants to engage the interviewers and give open-ended comments seems to suggest willingness and openness to speak frankly about the subject. Further, this study only assessed the extent of trust at a single time point and therefore one cannot make conclusions concerning trends in public trust or if results were particularly influenced by national media health care coverage at the time. However it does provide a point against which further studies can be evaluated as attempts are made to address the issue of trust in health care across the region.

In conclusion this study sought to examine the levels of public trust in the health care system in a small island developing Caribbean state. The study aimed to provide further insight into doctor-patient trust as they exist in a developing country, Trinidad \& Tobago. While individual health practitioners had trust scores that could be considered generally acceptable there was low trust in the health care system as a whole. When compared with developed countries, both individual practitioners and the health care system as a whole scored significantly lower in T\&T. These results may reflect the reality in the wider developing world, however, further studies of this nature are required in developing countries especially in the Caribbean. This study also highlighted the critical role of trust in the health care system. What may perhaps be the cause of the disparity of public trust results between the developed and developing world is not the availability of resources but how trust has been cultivated. Developed countries have identified the significance of trust and increased efforts towards cultivating and maintaining trust in health care 
practitioners and students. As a result, public trust levels have experienced a significant increase in some of these developed nations. The developing world in this regard appears to be lagging behind and should radically consider efforts to cultivate trust within their health care systems. 


\section{References}

Aldana JM, Piechulek H, Al-Sabir A. 2001. Client satisfaction and quality of health care in rural Bangladesh. Bull World Health Organ 79: 512-517.

Blendon RJ, Taylor H. 1989. Views on health care: public opinion in three nations. Health Aff (Millwood) 8:150-157.

Calnan M, Sanford E. 2004. Public trust in health care: the system or the doctor? Qual Saf Health Care 13: 92-97.

CARICOM Capacity Development Program (CCDP). 2009. National Census Report 2000, Trinidad \& Tobago. CARICOM Secretariat, Guyana. Retrieved from http://www.caricomstats.org/Files/Publications/NCR\%20Reports/Trinidad\%20an d\%20Tobago.pdf on 20-11-2014.

Checkland K, Marshall M, Harrison S. 2004. Re-thinking accountability: trust versus confidence in medical practice. Qual Saf Health Care 13:130-5.

Cruess S, Cruess R. 2004. Professionalism and Medicine's Social Contract with Society. Virtual Mentor 6. DOI: 10.1001/virtualmentor.2004.6.4.msoc1-0404. Accessed 1 April 2013.

Davies HT, Shields AV. 1999. Public trust and accountability for clinical performance: lessons from the national press reportage of the Bristol hearing. J Eval Clin Pract 5:335-42.

Donelan K, Dittus R, Buerhaus P, Dutwin D, DesRoches C. 2008. Public Perceptions of Nursing Careers: The Influence of the Media and Nursing Shortages. Nurs Econ 26: $143-150$. 
EKOS Research Associates. 2011. Shifting Public Perceptions of Doctors and Health Care, Final Report. http://www.afmc.ca/future-of-medical-education-incanada/postgraduate-project/pdf/AFMC_Final_Report_Final.pdf. Accessed 1 April 2013.

Gilson L. 2003. Trust and the development of health care as a social institution. Soc Sci Med 56: 1453-1468.

Gray B. 1997. Trust and trustworthy care in the managed care era. Health Aff (Millwood) 16: 34-49.

Handler J. 2000. Slave medicine and Obeah in Barbados, circa 1650 to 1834. New West Indian Guide/ Nieuwe West-Indische Gids 74: 57-90.

Hofstede G. 1984. Culture's consequences: international differences in work-related values. Sage Publications: Newbury Park, CA.

Ipsos Mori. 2012. Public Perceptions of the NHS Tracker Survey Wave Report. https://www.gov.uk/government/uploads/system/uploads/attachment_data/file/12 7101/Public-Perceptions-of-the-NHS-Tracker-Spring-2012-Report-FINALv1.pdf.pdf. Accessed 1 April 2013.

Jegede AS. 2007. What Led to the Nigerian Boycott of the Polio Vaccination Campaign? PLoS Med 4:e73. DOI: 10.1371/journal.pmed.0040073. Accessed 1 April 2013.

Kroeger A, Hernandez JM. 2003. Health services analysis as a tool for evidence-based policy decisions: the case of the Ministry of Health and Social Security in Mexico. Trop Med Int Health 8:1157-64.

Lee Y, Ng C, Aishah S, Ghazalie M, Ngiam J, Tai B, Lim M, Hughes K. 2007. Public Trust in Primary Care Doctors, the Medical Profession and the Health care 
System among Redhill Residents in Singapore. Ann Acad Med Singapore 36:65561.

Maynard A, Bloor K. 2003. Trust and performance management in the medical marketplace. J R Soc Med 96: 532-539.

McCollin D. 2009. World War II to Independence: Health, Services, and Women in Trinidad and Tobago, 1939-1962. In: De Barros J, Palmer S and Wright D, editors. Health and Medicine in the circum-Caribbean, 1800-1968. Routledge: New York.

Mechanic D, Schlesinger M. 1996. The impact of managed care on patients' trust in medical care and their physicians. JAMA 275:1693-1697.

Mechanic D. 1996. Changing Medical Organization and the Erosion of Trust. Milbank Q 74: 171-189.

Mechanic D. 2001. The Managed Care Backlash: Perceptions and Rhetoric in Health Care Policy and the Potential for Health Care Reform. Milbank Q 79: 35-54.

Mechanic, D. 2004. In my chosen doctor I trust. BMJ 2004; 329: 1413-19.

Myburgh N, Solanki G, Smith M, Lalloo R. 2005. Patient satisfaction with health care providers in South Africa: the influences of race and socioeconomic status. Int $J$ Qual Health Care 17: 473-477.

Pearson S, Raeke L. 2000. Patients’ Trust in Physicians: Many Theories, Few Measures, and Little Data. J Gen Intern Med 15: 509-513.

Phillips D. 1996. Medical professional dominance and client dissatisfaction - a study of doctor-patient interaction and reported dissatisfaction with medical care among 
female patients at four hospitals in Trinidad and Tobago. Soc Sci Med 42: 14191425.

Piette JD, Heisler M, Krein S, Kerr EA. 2005. The role of patient-physician trust in moderating medication nonadherence due to cost pressures. Arch Int Med 165:1749-55.

Shore DA. 2007. The Trust Crisis in Health care. Oxford University Press: New York.

Straten GF, Friele RD, Groenewegen PP. 2002 Public trust in Dutch health care. Soc Sci Med 55: 227-34.

van der Schee E, Braun B, Calnan M, Schnee M, Groenewegen PP. 2007. Public trust in health care: a comparison of Germany, The Netherlands, and England and Wales. Health Policy 81: 56-67.

van der Schee E, Groenewegen PP, Friele RD. 2006. Public trust in health care: a performance indicator? J Health Organ Manag 20: 468-476.

West Indian Royal Commission. 1945. West Indian Royal commission report: presented by the Secretary of state for the colonies to parliament by command of His Majesty, June 1945. H.M.S.O.: London.

World Health Organization. 2001. Macroeconomics and Health: Investing in Health for Economic Development. World Health Organization: Switzerland. World Health Organization. 2013. World Health Statistics 2013. World Health Organization: Switzerland. 
Table 1

Demographic characteristics of population sampled. Total sample size $=495$

$\%$ of sample \% of sample

\begin{tabular}{|c|c|c|c|}
\hline \multicolumn{2}{|l|}{ Age } & \multicolumn{2}{|l|}{$\begin{array}{l}\text { Health Service } \\
\text { Accessed }\end{array}$} \\
\hline $21-30$ & 46 & Health Centre & 13 \\
\hline $31-40$ & 24 & Public Hospital & 12 \\
\hline $41-50$ & 15 & Private Doctor & 57 \\
\hline $51-60$ & 10 & Private Hospital & 4 \\
\hline $61-70$ & 5 & Other & $<1$ \\
\hline \multicolumn{2}{|l|}{ Ethnicity } & \multicolumn{2}{|l|}{ Education } \\
\hline African & 27 & Primary & 9 \\
\hline Indian & 46 & Secondary & 58 \\
\hline Mixed & 24 & Tertiary & 32 \\
\hline Other & 1 & & \\
\hline \multicolumn{2}{|l|}{ Gender } & \multicolumn{2}{|l|}{ Residence } \\
\hline Male & 33 & Urban & 36 \\
\hline Female & 67 & Suburban & 34 \\
\hline & & Rural & 24 \\
\hline \multicolumn{4}{|l|}{ Religion } \\
\hline Christian & 56 & & \\
\hline Hindu & 24 & & \\
\hline Muslim & 9 & & \\
\hline Other & 9 & & \\
\hline
\end{tabular}

Note: In certain categories samples do not sum to $100 \%$ as in certain cases participants did not complete this category on questionnaire. 


\section{Table 2}

Percentage of persons sampled who agree with the following statements. Statements are grouped into five dimensions of trust.

\section{Patient Centred Focus of Providers}

Percentage (\%)

- Patients are taken seriously by healthcare providers

- Patients get enough attention

- Patients are listened to by healthcare providers

28

- Doctors spend enough time on their patients

\section{Effect of Polices within the Healthcare System}

- Patients won't be the victim of rising costs of health care 21

- Patients are able to pay for their own health care if they have to

- Medical help and patient care are compromised to shorten waiting lists

- Waiting times are never too long

- Cost-cutting in the healthcare system does not disadvantage patients

\section{Level of Expertise of Providers}

- Doctors can do everything

- The healthcare system has improved with new approaches of treatment and technology

- The education and training of doctors in this country is comparable to the world standard

- Doctors are well regulated in this country

\section{Quality of Care}

- Patients always get the right dose of their medicine

- Doctors are good at co-operating with each other

- Patients always get the right medicine

- Doctors carefully maintain confidentiality in treating with patients' medical information

- Patients are referred to the relevant specialist doctors in time

- Doctors always do enough tests

- Doctors always make the right diagnosis

\section{Communication \& Information Provision}

- Patients get sufficient information about the cause of their health problems

- Patients get sufficient \& correct information about the effects of their treatments

- Patients get sufficient and correct information about the various treatments that are available

- Doctors provide their patients with good guidance

- Doctors discuss medical issues fully with their patients 


\section{Table 3}

Thematic areas of concern with regards to the overall satisfaction within the health care system in Trinidad \& Tobago. (Derived from open-ended comments, $N=75$ )

\section{Theme}

Frequency

Percentage (\%)

Better Management, Accountability \&

34

44

Regulation

Better Patient Care

31

Waiting times

11

15

Public Care vs Private Practice

5

7

Health Promotion

2

3 


\section{Table 4a}

International Comparison of Public Perceptions of the Health Professions and the Health care System

\begin{tabular}{|c|c|c|c|c|c|}
\hline & T\&T & UK & $\begin{array}{l}\text { The } \\
\text { Netherlands }\end{array}$ & Germany & Singapore $+^{3}$ \\
\hline General Practitioners & 2.5 & 3.3 & 3.1 & 3 & $59.7 / 100$ \\
\hline Specialists & 2.6 & 3.3 & 3.1 & 3 & - \\
\hline Dentists & 2.5 & 3.4 & 3 & 3 & - \\
\hline Pharmacists & 2.5 & 3.4 & 3 & 2.7 & - \\
\hline Nurses & 2 & 3.3 & 2.9 & 2.7 & - \\
\hline Health Care system & 1.8 & $6 / 10 * 1$ & $6.7 / 10 * 2$ & - & $61.5 / 100$ \\
\hline
\end{tabular}

\section{Table 4b}

International Comparison of Five Dimensions of the Health Care System

\begin{tabular}{lcclll}
\hline & T\&T & UK & $\begin{array}{l}\text { The } \\
\text { Netherlands }\end{array}$ & Germany & Singapore ${ }^{3}$ \\
\hline Patient-Centered Focus & 1.7 & 2.4 & 2.5 & 2.3 & $60.1 / 100$ \\
Effect of Policies & 1.7 & 1.7 & 1.8 & 1.7 & $46.5 / 100$ \\
Expertise of Providers & 1.5 & 2.3 & 2.4 & 2.2 & $64.5 / 100$ \\
Quality of Care & 1.7 & 2.6 & 2.5 & 2.2 & $63.8 / 100$ \\
$\begin{array}{l}\text { Communication and } \\
\text { Information Provision }\end{array}$ & 1.8 & 2.4 & 2.6 & 2.3 & $59.2 / 100$ \\
\hline
\end{tabular}

*In these instances the mean is out of 10 but in all other cases the total is 4 .

+ In these instances the mean is out of 100 .

Scores were extracted from Calhan and Sanford 2004 ${ }^{1}$, Schee, Groenewegen and Friele 2006, Schee et al $2007^{2}$ and Lee et al $2007^{3}$. 
Table 5

International Comparison of Individual Statements of Five Dimensions of the Healthcare System

T\&T UK Germ Neths.

\section{Patient Centred Focus of Providers}

$\begin{array}{llllll}\text { - } & \text { Patients are taken seriously by healthcare } & 29 & 67 & 49.8 & 68.5\end{array}$ providers

- Patients get enough attention

$14 \quad 40 \quad 31.4 \quad 38.1$

- Patients are listened to by healthcare

28

$53.4 \quad 44.2$

55.8 providers

- Doctors spend enough time on their

19

$34.2 \quad 26.2$

40.7 patients

Effect of Polices within the Healthcare System

- Patients won't be the victim of rising costs of health care

21

22.3

14.2

10.5 of health care

- Patients are able to pay for their own health 21 care if they have to

- Medical help and patient care are 37

20

16.1 compromised to shorten waiting lists

- Waiting times are never too long

19.9

21.1

9.4

- Cost-cutting in the healthcare system does

13

24.3

12.9

10.5 not disadvantage patients

\section{Level of Expertise of Providers}

- Doctors can do everything

- The health care system has improved with 32

48.2

46.4 new approaches of treatment $\&$ technology

- Education \& training of doctors in this 25 77.2 country is comparable to the world standard 
Table 5 continued

Quality of Care

- Patients always get the right dose of their 15

15

$44.1 \quad 37.7$

46

medicine

- $\quad$ Doctors are good at co-operating with each 39

other

$32.1 \quad 20.4 \quad 29$

- Patients always get the right medicine

13

55.4

31.1

48.6

- Doctors carefully maintain confidentiality

48

$81.5 \quad 49.8$

68.3

in treating with patients' medical

information

- Patients are referred to the relevant

24

48.1

41.9

55.9 specialist doctors in time

- Doctors always do enough tests

20

49.9

$45.1 \quad 56.8$

- Doctors always make the right diagnosis

13

67

33.5

38.9

Communication \& Information Provision

- Patients get sufficient information about

21

52.7

41.8

56.6

the cause of their health problems

- Patients get sufficient and correct

17

44.1

39.5

53.4

information about the effects of their treatments

- Patients get sufficient and correct

24

36.6

40.7

54.6 information about the various treatments that are available

- Doctors provide their patients with good

37

56.6

41

62.8 guidance

27

53.3

43.3

59.1 their patients

- Patients show doctors respect

$54 \quad 19 *$

* Calhan and Sanford 2004

All other figures compare our results with Schee et al 2007. 


\section{Legends for Figures}

Figure 1: Bar graph demonstrating level of trust for various health professionals. Graphs A-G depict the percentages response to the various points on a four point Likert scale. Graph H uses a calculated mean to compare overall trust among the various professions. GP=General Practioners; SPE=Medical Specialists; DEN=Dentists; PHS=Pharmacists; NRE $=$ Nurses; $C T=$ Commentary Therapists and $\mathrm{HS}=$ the overall care system.

Figure 2: Bar graph depicting the mean scores on the five dimensions of trust assessed. PC= Patient Centred Focus of Health care providers; QC = Quality of Care; PLE= Level of Expertise of Health care providers; POL=Impact of Polies on the Health care System; CI=Communication \& Information Provision 